\title{
Soma térmica e estádios de desenvolvimento da planta de grupos de cultivares de arroz irrigado
}

\author{
Silvio Steinmetz ${ }^{\left.1{ }^{*}\right)}$, Santiago Vianna Cuadra ${ }^{1}$, Ivan Rodrigues de Almeida ${ }^{1}$, Ariano Martins de Magalhães Júnior ${ }^{1}$ e Paulo Ricardo \\ Reis Fagundes ${ }^{1}$ \\ ${ }^{1}$ Embrapa Clima Temperado, Rodovia BR 392, km 78, Caixa Postal 403, CEP 96.010-971 Pelotas, RS. E-mails: silvio.steinmetz@embrapa.br, \\ santiago.cuadra@embrapa.br, ivan.almeida@embrapa.br, ariano.martins@embrapa.br e paulo.fagundes@embrapa.br \\ ${ }^{(*)}$ Autor para correspondência
}

\section{INFORMAÇÕES}

\section{História do artigo:}

Recebido em 29 de Junho de 2017

Aceito em 27 de Dezembro de 2017

Termos para indexação:

Oryza sativa L.

graus-dia

fenologia

manejo da cultura

\section{RESUMO}

A recomendação da pesquisa é que as práticas de manejo do arroz irrigado sejam realizadas de acordo com os estádios de desenvolvimento da planta. O problema é que a ocorrência desses estádios é variável, por ser dependente da temperatura. Por isso, é preferível estimá-los por meio de soma térmica, ou graus-dia, ao invés do número de dias do calendário. O objetivo deste trabalho foi determinar o número de dias e a soma térmica necessários para atingir seis estádios de desenvolvimento da planta, de quatro grupos, envolvendo 34 cultivares. Experimentos de campo foram conduzidos na Embrapa Clima Temperado (ETB), município de Capão do Leão, RS, durante doze safras. Dez plantas de cada cultivar foram marcadas e tiveram o desenvolvimento acompanhado durante o ciclo. Os graus-dia foram calculados através do somatório da diferença entre a temperatura média diária (Tm) e a temperatura base inferior $(\mathrm{Tb})$ de $11^{\circ} \mathrm{C}$, da emergência até a data de cada estádio. Os resultados indicam que o número de dias e a soma térmica necessários para atingir os seis estádios da planta variam de acordo com o comprimento de ciclo das cultivares, sendo menores no grupo Muito Precoce, intermediários nos grupos Precoce e Médio e maiores no grupo Tardio.

(c) 2017 SBAgro. Todos os direitos reservados.

\section{Introdução}

O Estado do Rio Grande do Sul é o maior produtor de arroz irrigado do Brasil, tendo contribuído, na safra 2016/2017, com 79\% da produção nacional (CONAB, 2017). Embora os níveis de produtividade sejam relativamente altos $\left(7,83 \mathrm{t} \mathrm{ha}^{-1}\right)$, acredita-se que estes possam ser ainda maiores se forem melhorados alguns aspectos relacionados com o manejo da cultura. Para isso, é importante que a época de aplicação de uma determinada prática cultural, como a adubação nitrogenada em cobertura, o manejo da água, o controle de insetos-praga e de doenças, ou o momento da colheita, seja feita no estádio de desenvolvimento da planta mais apropriado (SOSBAI, 2016).

O problema é que a ocorrência desses estádios, especialmente o de diferenciação da panícula (R1), é muito variável por ser dependente da temperatura (STANSEL, 1975; WILSON JR. et al., 2015). Por isso, é preferível expressar-se o estádio R1 e os demais estádios de desenvolvimento da planta em dias, porém estimados por meio de graus-dia 
(GD) ou soma térmica, ao invés do número de dias do calendário (STRECK et al., 2006a; STEINMETZ et al., 2009a; 2013b). Por essa razão, foi desenvolvido um programa denominado GD Arroz (http://www.agromet.cpact.embrapa. br) que permite estimar a data de ocorrência de seis estádios de desenvolvimento da planta visando o manejo da cultura (STEINMETZ et al., 2015). Para subsidiar esse programa é importante determinar-se, em condições de campo, a soma térmica necessária para atingir os principais estádios de desenvolvimento da planta das novas cultivares lançadas no mercado, como o fizeram Steinmetz et al. (2009b).

O conhecimento da época de ocorrência dos subperíodos críticos da planta a determinados estresses abióticos, como baixas ou altas temperaturas, por exemplo, também pode útil para: - diminuir o efeito de baixas temperaturas pela elevação da lâmina de água entre os estádios de emborrachamento (R2) até o início da floração (R4) para aumentar o seu efeito termorregulador (SOSBAI, 2016); - avaliar a influência de altas temperaturas do ar sobre a esterilidade de espiguetas ou a produtividade de grãos (PRASAD et al., 2006); - estabelecer a relação entre baixas temperaturas do ar e produtividade (STEINMETZ et al., 2013a).

Em função do exposto, o objetivo deste trabalho foi determinar o número de dias e a soma térmica necessários para atingir seis dos mais importantes estádios de desenvolvimento da planta, de quatro grupos de cultivares de arroz irrigado.

\section{Material e Métodos}

Experimentos de campo foram realizados na Estação Experimental Terras Baixas (ETB) da Embrapa Clima Temperado, em Capão do Leão, RS (latitude de 3152' S; longitude de $52^{\circ} 21^{\prime} \mathrm{W}$ e altitude de $13 \mathrm{~m}$ ), durante um período de doze safras (2004/2005 a 2015/2016). O clima local, segundo a classificação climática de Köppen, é do tipo Cfa, que corresponde ao subtropical úmido, com verões quentes e sem estação seca definida (WREGE et al., 2011). o solo da área experimental é classificado como Planossolo Háplico eutrófico típico (SANTOS et al., 2006). As parcelas tinham $5 \mathrm{~m}$ de comprimento e 1,58m de largura, constando de 9 linhas espaçadas de $17,5 \mathrm{~cm}$. As adubações de base e em cobertura e os demais tratos culturais seguiram as recomendações da SOSBAI (2003) para a safra 2004/05, e as indicações vigentes da SOSBAI para as safras seguintes. Considerou-se como data de emergência quando em torno de $50 \%$ das plântulas da parcela eram visíveis acima do nível do solo.

Em geral, foram utilizadas doze cultivares e seis épocas de semeadura (de início de setembro a meados de dezembro) em cada safra. Entretanto, ao longo das safras, algumas cultivares foram sendo substituídas por outras, fazendo com que seja variável o números de safras de cada cultivar. Neste trabalho foram avaliadas 34 cultivares, de ciclos distintos, de acordo com a SOSBAI (2016), sendo três de ciclo Muito Precoce (MP), 13 de ciclo Precoce (P), 16 de
Tabela 1. Cultivares pertencentes a cada grupo, indicando o comprimento médio do ciclo de acordo com a SOSBAI ${ }^{(*)}$, entre parênteses, e números de safras em que os dados foram coletados, entre colchetes.

\begin{tabular}{|c|c|c|c|}
\hline \multicolumn{4}{|c|}{ Cultivares pertencentes a cada grupo } \\
\hline Muito Precoce (MP) & Precoce $(P)$ & Médio (M) & Tardio (T) \\
\hline IRGA 421(95) [7] & BRS 6 "Chui" (110) [5] & BRS Pelota (125) [6] & SCS BRS Tio Taka (141) [6] \\
\hline BRS Atalanta (100) [12] & BRS Querência (110) [12] & BRSCIRAD 302 (128) [3] & Epagri 109 (142) [4] \\
\hline \multirow[t]{14}{*}{ BRS Ligeirinho (95) [2] } & BRS Pampa (118) [8] & BRS Sinuelo CL (130) [7] & \\
\hline & BRS Firmeza(120) [5] & BR-IRGA 410 (123) [4] & \\
\hline & IRGA 417 (115) [9] & BR-IRGA 409 (126) [5] & \\
\hline & IRGA 422 CL (120) [3] & IRGA 429 (124) [1] & \\
\hline & IRGA 423 (120) [3] & IRGA 426 (125) [3] & \\
\hline & IRGA $430(120)$ [1] & IRGA 428 CL (125) [2] & \\
\hline & Avaxi CL (120) [7] & Lexus CL (128) [3] & \\
\hline & Inov CL (120) [7] & BRS 7 “Taim” (130) [5] & \\
\hline & Titan CL (120) [3] & BRS Bojuru (135) [2] & \\
\hline & Guri Inta CL (120) [3] & BRS Fronteira (135) [8] & \\
\hline & Puitá Inta CL (120) [5] & IRGA 424 (132) [8] & \\
\hline & & IRGA 424 RI (133) [1] & \\
\hline & & IRGA 425 (132) [3] & \\
\hline & & IRGA 427 (136) [2] & \\
\hline
\end{tabular}

${ }^{*}$ ) SOSBAI = Sociedade Sul-Brasileira de Arroz Irrigado - Recomendações Técnicas da Pesquisa para o Sul do Brasil. 
Tabela 2. Número médio de dias da emergência a cada um dos seis estádios de desenvolvimento da planta e porcentagem do ciclo total, entre parênteses, de quatros grupos de cultivares de arroz irrigado, obtidos em diversas safras, durante doze anos agrícolas (2004/2005 a 2015/2016), em Capão do Leão, RS.

\begin{tabular}{lllllll}
\multicolumn{1}{c}{ Grupo } & \multicolumn{6}{c}{ Número médio de dias da emergência ao estádio } \\
& V4 & R1 & R2 & R4 & R8 & R9 \\
Muito Precoce (MP) & B 20 (21) & C 44 (46) & D 58 (60) & D 72 (75) & D 91 (95) & D 96 (100) \\
Precoce (P) & AB 20 (18) & B 56 (50) & C 74 (66) & C 86 (77) & C 105 (94) & C 112 (100) \\
Médio (M) & B 21 (17) & B 61 (50) & B 81 (67) & B 94 (78) & B 114 (94) & B 121 (100) \\
\hline Tardio (T) & A 24 (17) & A 78 (54) & A 103 (71) & A 117 (81) & A 139 (96) & A 145 (100) \\
\hline
\end{tabular}

V4= planta com 4 folhas; R1= diferenciação da panícula; R2= formação do colar da folha bandeira (emborrachamento); R4= antese (uma ou mais espiguetas); R8= maturidade de um grão isolado; $\mathrm{R} 9=$ maturidade completa dos grãos da panícula. Valores antecedidos por letras iguais não diferem estatisticamente entre si pelo teste de Kruskal Wallis (a 95\% de confiança).

ciclo Médio (M) e duas de ciclo Tardio (T) (Tabela 1).

Dez plantas de cada cultivar foram marcadas (no colmo principal) e tiveram o desenvolvimento acompanhado durante todo o ciclo, caracterizando-se cada estádio de acordo com a escala proposta por Counce et al. (2000). Foram feitas de duas a três leituras por semana. Datas médias para cada estádio foram obtidas a partir das observações nas dez plantas. O estádio R1 (diferenciação da panícula) foi determinado pelo método descrito por Steinmetz et al. (2009a).

Os seis estádios considerados neste trabalho foram: V4 - planta com quatro folhas; R1 - diferenciação da panícula; R2 - formação do colar da folha bandeira (emborrachamento); R4 - antese (uma ou mais espiguetas); R8 - maturidade de um grão isolado; R9 - maturidade completa dos grãos da panícula. Para melhor caracterizar o comportamento fenológico dos quatro grupos de cultivares foram estabelecidos seis subperíodos subsequentes de desenvolvimento da planta (E-V4; V4-R1; R1-R2; R2-R4; R4-R8 e R8-R9). Também, estabelecerem-se três períodos mais abrangentes denominando-os, respectivamente, de período vegetativo (E-R1), período reprodutivo 1 (R1-R4) e período reprodutivo 2 (R4-R9). A razão disso é que, antes do trabalho de Counce et al. (2000), consideravam-se os períodos E-R1, R1R4 e R4-R9, respectivamente, como fase vegetativa, fase reprodutiva e fase de maturação (YOSHIDA, 1981). Na escala de Counce et al. (2000), o primeiro período corresponde ao período vegetativo e os outros dois fazem parte do período reprodutivo.

Os graus-dia ( ${ }^{\circ} \mathrm{C}$ dia) foram calculados através do somatório da diferença entre a temperatura média diária do ar (Tm) e a temperatura base inferior (Tb) de $11^{\circ} \mathrm{C}$ (INFELD et al., 1998), da emergência até a data de cada estádio. A Tm foi obtida pela média atitmética entre as temperaturas máxima (Tx) e mínima (Tn). Antes de calcular-se a Tm, foram aplicados os limites de $34{ }^{\circ} \mathrm{C}$ e de $21^{\circ} \mathrm{C}$ (SLATON et al., 1996), respectivamente, para a Tx e a Tn, ou seja, valores superiores a estes foram desconsiderados. Os graus-dia para cada estádio, das cultivares de cada grupo, representam a média das seis épocas de semeadura, em cada safra, e das várias safras em que a cultivar foi utilizada.

A comparação dos grupos de cultivares, quanto ao número de dias e à soma térmica para atingir os seis estádios de desenvolvimento da planta, foi feita utilizando o método não-paramétrico de Kruskal Wallis, uma vez que os dados não apresentam distribuição normal (SIEGEL \& CASTELLAN JR., 2006).

\section{Resultados e Discussão}

O número médio de dias para atingir cada um dos seis estádios indicou diferenças acentuadas entre os grupos, excetuando-se o estádio V4, devido ao comprimento do ciclo das cultivares pertencentes a esses grupos. 0 estádio R1, por exemplo, foi atingido aos 44, 56, 61 e 78 dias após a emergência, respectivamente, para os grupos Muito Precoce (MP), Precoce (P), Médio (M) e Tardio (T) (Tabela 2 e Figura 1). O teste estatístico indicou que os grupos T e MP foram diferentes entre si e diferenciaram-se, também, dos grupos M e P. Entretanto, não houve diferença estatística entre esses dois últimos grupos (Tabela 2). A provável explicação para a semelhança no número de dias para atingir o estádio R1 dos grupos M e P esteja no fato de que a maioria (70\%) das cultivares do grupo P utilizadas neste estudo tenham sido registradas pelos seus obtentores como tendo o ciclo total (da emergência à maturação) de 120 dias, portanto, no limite superior de duração de ciclo para esse grupo, que vai de 106 a 120 dias (SOSBAI, 2016). Por outro lado, no grupo $\mathrm{M}$, cerca de $30 \%$ das cultivares utilizadas têm ciclos abaixo de 125 dias, situando-se, portanto, próximo do início do período indicado pela Sosbai (2016), que vai de 121 a 135 dias. 
Figura 1. Número médio de dias da emergência aos distintos estádios de desenvolvimento da planta de quatro grupos de cultivares de arroz irrigado, sendo que: E= emergência (50\%); V4= estádio de 4 folhas; R1= diferenciação da panícula; R2= formação do colar da folha bandeira (emborrachamento); R4= antese (uma ou mais espiguetas); R8= maturidade de um grão isolado; R9= maturidade completa dos grãos da panícula. Capão do Leão, RS, 2004/2005 a 2015/2016.

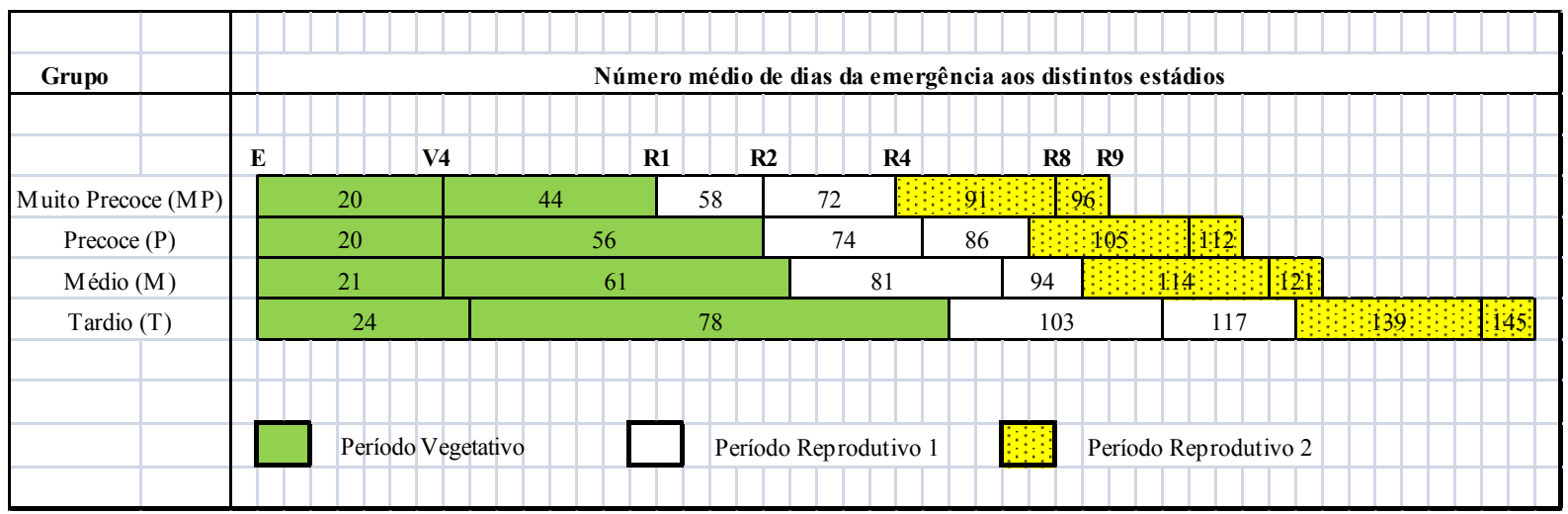

Por ser particularmente influenciado pela temperatura, o estádio R1 pode apresentar valores diferentes, independentemente do grupo ao qual a cultivar pertence, de acordo com a época de semeadura. Semeaduras antecipadas e tardias tendem, respectivamente, a alongar e a encurtar o subperíodo da emergência ao estádio R1 (STEINMETZ et al., 2009ab; SINGH et al., 2012). O fotoperíodo é outro fator que pode interferir na duração do período vegetativo, dependendo da sensibilidade da cultivar e da época de semeadura (YOSHIDA, 1981; STRECK et al., 2006b).

O período vegetativo (E-R1) representou cerca de $50 \%$ do ciclo total (E-R9) na média dos quatro grupos, variando de $46 \%$ para o grupo Muito Precoce a 54\% para o grupo Tardio (Tabela 2 e Figura 1). Para o subperíodo E-R2, os valores de $60 \%$ e $71 \%$ do ciclo total, respectivamente, para os grupos Muito Precoce e Tardio são semelhantes a 55\% para a cultivar IRGA 421 (Muito Precoce) e a 75\% para a cultivar Epagri 109 (Tardio), obtidos por Streck et al. (2006a).

O estádio R9, que corresponde à maturação completa dos grãos da panícula, também indicou diferença marcante entre os grupos, tendo sido atingido aos 96, 112, 121 e 145 dias após a emergência, respectivamente, para os grupos MP, P, M e T (Tabela 2 e Figura 1). Esses valores, que representam a média de seis épocas de semeadura, em cada safra, situaram-se dentro das faixas de comprimento de ciclo indicadas em SOSBAI (2016). Os quatro grupos de cultivares foram estatisticamente diferentes entre si quanto ao número médio de dias para atingir os estádios R2, R4, R8 e R9 (Tabela 2).

Quando se considerou a soma térmica, ou graus-dia, o teste estatístico indicou que, do estádio R1 ao R9, os quatro grupos de cultivares foram diferentes entre si (Tabela $3 \mathrm{e}$ Figura 2). Os valores de soma térmica obtidos neste trabalho, para a maioria dos estádios, são semelhantes àqueles de Watson et al. (2004) e também com os de Steinmetz et al. (2009b). Por outro lado, situam-se abaixo dos indicados por
Streck et al. (2006a) para atingir o estádio R9, por exemplo, de algumas cultivares, de diferentes grupos.

O subperíodo de maiores diferenças entre os grupos de cultivares foi o compreendido entre o estádio de quatro folhas e a diferenciação da panícula (V4-R1), indicando uma variação de 30 dias (125\%) entre entre os grupos Tardio (54 dias) e Muito Precoce (24 dias). o segundo período de maior diferença entre os grupos foi o compreendido entre o estádio de diferenciação da panícula e o emborrachamento (R1-R2), indicando uma variação de 11 dias (79\%) entre entre esses dois grupos (Tabela 4 e Figura 3). Nos demais subperíodos a diferença foi pequena entre os quatro grupos de cultivares. Comportamento semelhante ocorreu com a soma térmica, indicando para o subperíodo R1-R2, por exemplo, uma diferença de $76^{\circ} \mathrm{C}$ dia (36\%) entre os grupos Tardio $\left(290{ }^{\circ} \mathrm{C}\right.$ dia) e Muito Precoce $\left(214{ }^{\circ} \mathrm{C}\right.$ dia $)$ (Tabela 5). Esses resultados estão de acordo com os obtidos anteriormente por Steinmetz et al. (2009b).

Quando se considerou apenas três períodos de desenvolvimento da planta, os resultados indicaram que as maiores diferenças entre os grupos de cultivares foram entre a emergência e a diferenciação da panícula (E-R1), indicando uma variação de 34 dias (77\%) entre os grupos Tardio (78 dias) e Muito Precoce (44 dias). O segundo período de maior diferença entre os grupos foi entre o estádio de diferenciação da panícula e a antese (R1-R4), indicando uma variação de 11 dias (38\%) entre esses dois grupos (Tabela 6 e Figura 4). Utilizando-se a soma térmica observou-se um comportamento semelhante. Para o período E-R1, por exemplo, ocorreu uma diferença de $474{ }^{\circ} \mathrm{C}$ dia (96\%) entre os grupos Tardio $\left(968^{\circ} \mathrm{C}\right.$ dia) e Muito Precoce $\left(494{ }^{\circ} \mathrm{C}\right.$ dia) (Tabela 7). Embora os estádios de desenvolvimento da planta utilizados não tenham sido exatamente os mesmos, pode-se inferir que os resultados deste trabalho foram semelhantes aos obtidos por Singh et al. (2012).

Uma das dificuldades encontradas para comparar os 
Figura 2. Graus-dia ( ${ }^{\circ} \mathrm{C}$ dia) médios da emergência aos principais estádios de desenvolvimento da planta de quatro grupos de cultivares de arroz irrigado, sendo que: V4= estádio de 4 folhas; R1= diferenciação da panícula; R2= formação do colar da folha bandeira (emborrachamento); R4= antese (uma ou mais espiguetas); R8= maturidade de um grão isolado; R9= maturidade completa dos grãos da panícula. Capão do Leão, RS, 2004/2005 a 2015/2016.

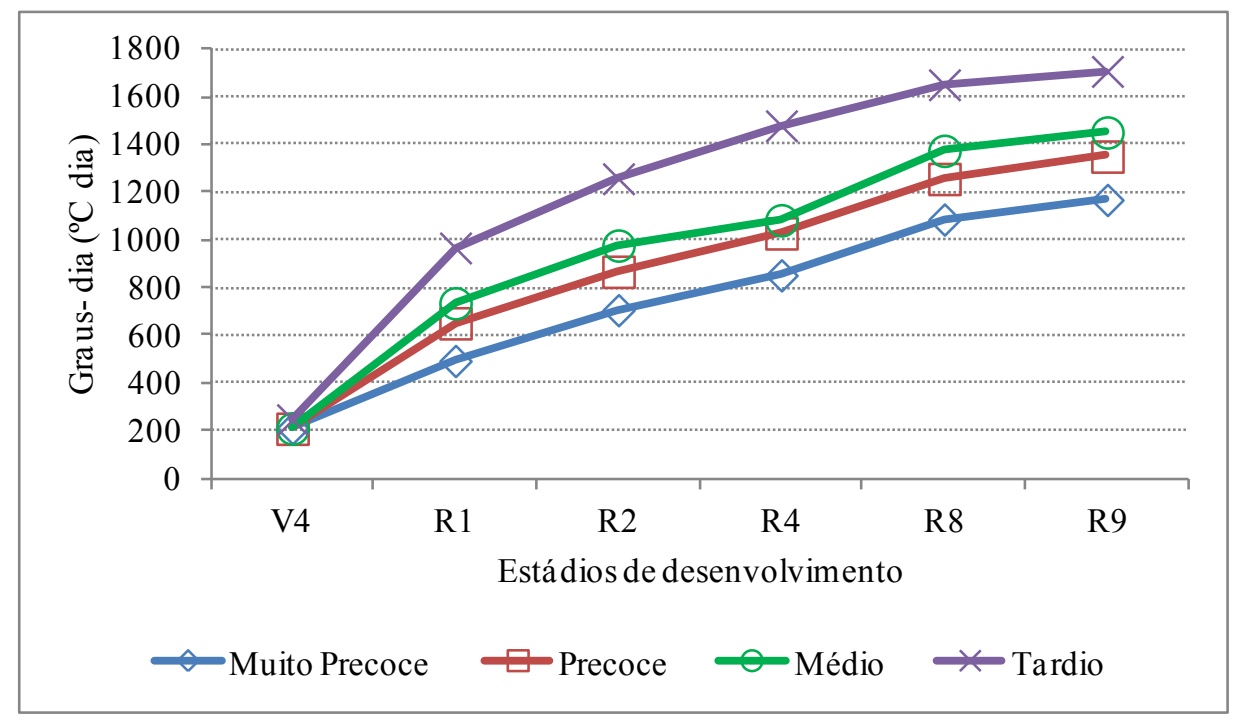

Tabela 3. Graus-dia ( ${ }^{\circ} \mathrm{C}$ dia) médios da emergência a cada um dos seis estádios de desenvolvimento da planta e porcentagem do ciclo total, entre parênteses, de quatro grupos de cultivares de arroz irrigado, obtidos em diversas safras, durante doze anos agrícolas (2004/2005 a 2015/2016), em Capão do Leão, RS.

\begin{tabular}{lllllll}
\multicolumn{1}{c}{ Grupo } & \multicolumn{5}{c}{ Graus-dia $\left({ }^{\circ} \mathrm{C}\right.$ dia) médio da emergência ao estádio } \\
V4 & R1 & R2 & R4 & R8 & R9 \\
\hline Muito Precoce (MP) & AB 212 (18) & D 494 (42) & D 707 (60) & D 853 (73) & D 1087 (93) & D 1169 (100) \\
Precoce (P) & B 210 (16) & C 652 (48) & C $868(64)$ & C 1029 (76) & C 1257 (93) & C 1351(100) \\
\hline Médio (M) & B 211 (15) & B 736 (51) & B $978(67)$ & B 1084 (75) & B 1375 (95) & B 1452 (100) \\
\hline Tardio (T) & A 248 (15) & A 968 (57) & A 1258 (74) & A 1480 (87) & A 1652 (97) & A 1708 (100) \\
\hline
\end{tabular}

V4=planta com 4 folhas; R1= diferenciação da panícula; R2= formação do colar da folha bandeira (emborrachamento); R4= antese (uma ou mais espiguetas); R8= maturidade de um grão isolado; R9= maturidade completa dos grãos da panícula. Valores antecedidos por letras iguais não diferem estatisticamente entre si pelo teste de Kruskal Wallis (a 95\% de confiança).

Tabela 4. Número médio de dias entre os principais estádios de desenvolvimento da planta, de quatro grupos de cultivares de arroz irrigado, obtido em diversas safras, durante o período de doze anos agrícolas (2004/2005 a 2015/2016), em Capão do Leão, RS.

\begin{tabular}{lcccccc}
\multicolumn{1}{c}{ Grupo } & \multicolumn{7}{c}{ Número médio de dias entre os principais estádios } \\
\cline { 2 - 6 } & E-V4 & V4-R1 & R1-R2 & R2-R4 & R4-R8 & R8-R9 \\
\hline Média Precoce (MP) & 20 & 24 & 14 & 14 & 19 & 5 \\
\hline Precoce (P) & 20 & 36 & 18 & 12 & 19 & 7 \\
Médio (M) & 21 & 40 & 20 & 13 & 20 & 7 \\
Tardio (T) & 24 & 54 & 25 & 14 & 22 & 6 \\
\hline
\end{tabular}

E-V4=da emergência ao estádio de 4 folhas; V4-R1= do estádio de 4 folhas à diferenciação da panícula; R1-R2=dadiferenciação da panícula à formação do colar da folha bandeira (emborrachamento); R2-R4= do emborrachamento à antese (uma ou mais espiguetas); R4-R8= da antese à maturidade de um grão isolado; R8-R9= da maturidade de um grão isolado à maturidade completa dos grãos da panícula. 
Figura 3. Número médio de dias dos distintos subperíodos de desenvolvimento da planta de quatro grupos de cultivares de arroz irrigado, sendo que: $\mathrm{E}=$ emergência (50\%); V4= estádio de 4 folhas; R1= diferenciação da panícula; $\mathrm{R} 2=$ formação do colar da folha bandeira (emborrachamento); $\mathrm{R} 4=$ antese (uma ou mais espiguetas); R8= maturidade de um grão isolado; R9= maturidade completa dos grãos da panícula. Capão do Leão, RS, 2004/2005 a 2015/2016.

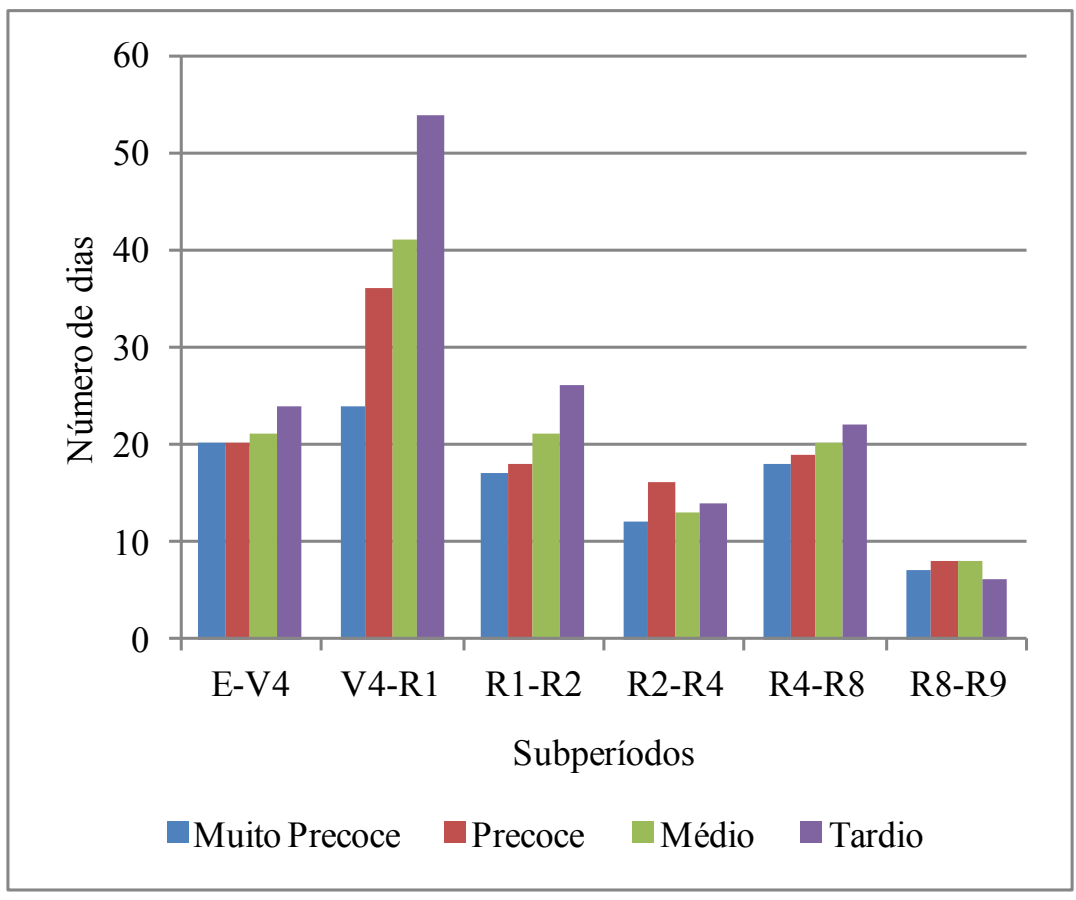

Tabela 5. Graus-dia ( ${ }^{\circ} \mathrm{C}$ dia) médios entre os principais estádios de desenvolvimento da planta, de quatro grupos de cultivares de arroz irrigado, obtidos em diversas safras, durante o período de doze anos agrícolas (2004/2005a 2015/2016), em Capão do Leão, RS.

\begin{tabular}{lcccccc}
\multicolumn{1}{c}{ Grupo } & \multicolumn{7}{c}{ Graus-dia $\left({ }^{\circ} \mathrm{C}\right.$ dia) médio entre os principais estádios } \\
& E-V4 & V4-R1 & R1-R2 & R2-R4 & R4-R8 & R8-R9 \\
\hline Média Precoce (MP) & 212 & 282 & 213 & 146 & 234 & 82 \\
\hline Precoce (P) & 205 & 442 & 216 & 161 & 228 & 94 \\
\hline Médio (M) & 211 & 525 & 242 & 106 & 291 & 77 \\
\hline Tardio (T) & 248 & 720 & 290 & 222 & 172 & 56 \\
\hline
\end{tabular}

E-V4= da emergência ao estádio de 4 folhas; V4-R1= do estádio de 4 folhas à diferenciação da panícula; R1-R2= da diferenciação da panícula à formação do colar da folha bandeira (emborrachamento); R2-R4= do emborrachamento à antese (uma ou mais espiguetas); R4-R8= da antese à maturidade de um grão isolado; R8-R9= da maturidade de um grão isolado à maturidade completa dos grãos da panícula.

Tabela 6. Número médio de dias nos períodos vegetativo (E-R1), reprodutivo 1 (R1-R4) e reprodutivo 2 (R4-R9), de quatro grupos de cultivares de arroz irrigado, obtido em diversas safras, durante doze anos agrícolas (2004/2005 a 2015/2016), em Capão do Leão, RS.

\begin{tabular}{lccc}
\multicolumn{1}{c}{ Grupo } & \multicolumn{3}{c}{ Número médio de dias nos periodos } \\
& E-R1 (PV) & R1-R4 (PR1) & R4-R9 (PR2) \\
\hline Média Precoce (MP) & 44 & 28 & 24 \\
\hline Precoce (P) & 56 & 30 & 26 \\
Médio (M) & 61 & 33 & 27 \\
\hline Tardio (T) & 78 & 39 & 28 \\
\hline
\end{tabular}

$\mathrm{E}-\mathrm{R} 1=\mathrm{da}$ emergência à diferenciação da panícula (Período vegetativo -PV); R1-R4= da diferenciação da panícula à antese (Período reprodutivo 1 - PR1); R4-R9= da antese à maturidade completa dos grãos da panícula (Período reprodutivo 2 - PR2) 
Tabela 7. Graus-dia (ํ C dia) médios nos períodos vegetativo (E-R1), reprodutivo 1 (R1-R4) e reprodutivo 2 (R4-R9), de quatro grupos de cultivares de arroz irrigado, obtidos em diversas safras, durante doze anos agrícolas (2004/2005 a 2015/2016), em Capão do Leão, RS.

\begin{tabular}{lccc} 
& & Graus-dia $\left({ }^{\circ} \mathbf{C}\right.$ dia) médios nos períodos & \\
& Erupo & R1-R4 (PR1) & R4-R9 (PR2) \\
\hline Média Precoce (MP) & 494 & 359 & 316 \\
\hline Precoce (P) & 652 & 377 & 322 \\
\hline Médio (M) & 736 & 348 & 368 \\
\hline Tardio (T) & 968 & 512 & 228 \\
\hline
\end{tabular}

E-R1= da emergência à diferenciação da panícula (Período vegetativo - PV); R1-R4= da diferenciação da panícula à antese (Período reprodutivo 1 - PR1); R4-R9= da antese à maturidade completa dos grãos da panícula (Período reprodutivo 2 - PR2).

Figura 4. Número médio de dias de três períodos de desenvolvimento da planta de quatro grupos de cultivares de arroz irrigado, sendo que: E-R1= Período vegetativo (PV); R1-R4= Período reprodutivo 1 (PR1); R4-R9= Período reprodutivo 2 (PR2). Capão do Leão, RS, 2004/2005 a 2015/2016.

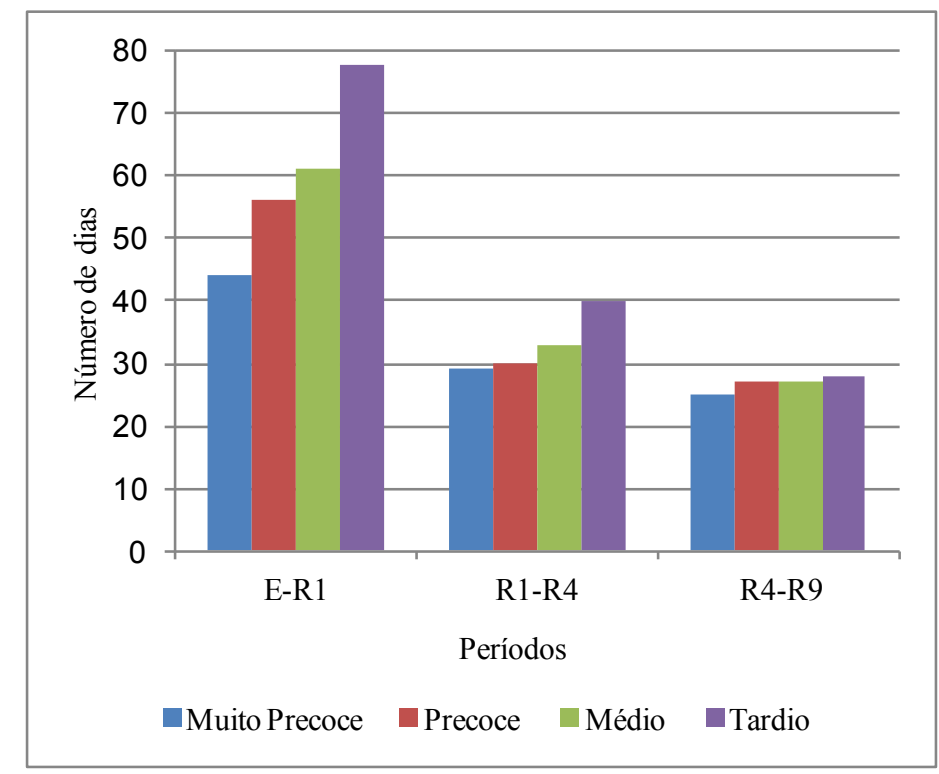

resultados com os obtidos por outros autores diz respeito à duração do período vegetativo, que neste trabalho foi da emergência à diferenciação da panícula (E-R1), enquanto que outros autores assumiram que o mesmo foi da emergência ao emborrachamento (E-R2) (WATSON et al., 2004; STRECK et al., 2006a). É provável que isso se deva ao fato do estádio R2 ser facilmente identificado a campo, sem a necessidade de fazer-se a amostragem destrutitiva de plantas, como ocorre para determinar-se o estádio R1 (STANSEL, 1975; STEINMETZ et al., 2009a). O problema é que a diferença entre os estádios R1-R2 pode ser acentuada. Nesse estudo ela variou entre 14 e 25 dias, respectivamente, para os grupos Muito Precoce e Tardio (Tabela 4). Dessa forma, quando há necesidade de determinar-se a duração do período vegetativo com maior acurácia, visando alguma prática de manejo, recomenda-se utilizar um método que permita determinar o estádio de diferenciação da panícula (R1) e, se possível, o de iniciação da panícula (IP). Este é o caso, por exemplo, da adubação nitrogenada em cobertura (ANC), que a SOSBAI (2016) recomenda que seja aplicada no estádio de iniciação da panícula (R0). Como esse está- dio é difícil de ser visualizado diretamenta na planta, em condições de lavoura, Steinmetz et al. (2014; 2015) sugerem utilizar como referência o estádio R1, visível a olho nu, que ocorre, em média, quatro dias após o estádio R0 (DE CARLI, 2016).

Os resultados obtidos são um avanço em relação aos de Steinmetz et al. (2009) pelo fato de terem sido avaliados quatro grupos de comprimento de ciclo (34 cultivares), ao invés de três grupos (16 cultivares), gerando informações fenológicas e somas térmicas necessárias para atingir os principais estádios de desenvolvimento, de diversas cultivares que foram recentemente lançadas no mercado. Estudos complementares são necessários visando enquadrar essas 34 cultivares nos sete subgrupos do programa GD Arroz (STEINMETZ et al., 2015).

\section{Conclusões}

- O número de dias e a soma térmica necessários para atingir os diferentes estádios de desenvolvimento da planta variam de acordo com o comprimento de ciclo das cul- 
tivares, sendo menores no grupo Muito Precoce, intermediários nos grupos Precoce e Médio e maiores no grupo Tardio.

- O período vegetativo representa em torno da metade do ciclo total, e é o que apresenta as maiores diferenças entre os quatro grupos de cultivares estudados, quando comparado aos períodos reprodutivos 1 e 2 .

- A soma térmica necessária para atingir os principais estádios de desenvolvimento da planta, de quatro grupos de cultivares, incluindo diversas delas lançadas recentemente no mercado, é adequada para o ajuste de modelos que simulam a fenologia da cultura.

\section{Agradecimentos}

Os autores agradecem às pessoas que colaboraram com esse trabalho, dentre as quais destacam-se: - os estagiários da Embrapa Clima Temperado que ajudaram na obtenção dos dados fenológicos ao longo dos anos: Alexandre N. Deibler; Anderson B. Schneider; André da R. Ulguim; Eduardo Goulart; Felipe L. de L. Nobre; Igor N. Schneid; Jackson B. A. Pintanel; Jonathan G. Oliveira; Rafael C. Santos; Shemene J. S. A. Audeh; Silas S. Costa;- a Assistente Denise D. Dos Santos pelo auxílio na tabulação dos dados; - o Pesquisador Ricardo A. Valgas pela análise estatística dos dados.

\section{Referências}

COMPANHIA NACIONAL DE ABASTECIMENTO (CONAB). Acampanhamento da safra brasileira - grãos. V.4 - Safra 2016/2017 - N. 9 - Nono levantamento - Junho 2017. Disponível em : <http:// www.conab.gov.br/OlalaCMS/uploads/arquivos/17_06_08_09_02_48 boletim_graos_junho_2017.pdf>. Acesso em 12 jun. 2017.

COUNCE, P.A.; KEISLING, T.C.; MITCHELL, A.J. A uniform, objective, and adaptive system for expressing rice development. Crop Science, Madison, v. 40, n. 2, p. 436-443, 2000.

DE CARLI, C.; STEINMETZ, S.; STRECK, N. A.; MARCHESAN, E.; SILVA, M. R. da. Número de dias e de graus-dia entre a iniciação e a diferenciação da panícula de cultivares de arroz irrigado. Ciência Rural, Santa Maria, v. 46, n. 3, p. 428-433, mar., 2016.

INFELD, J.A.; SILVA, J.B. da; ASSIS, F.N. de. Temperatura-base e grausdia durante o período vegetativo de três grupos de cultivares de arroz irrigado. Revista Brasileira de Agrometeorologia, Santa Maria, v. 6, n. 2, p. 187-191, 1998 .

PRASAD, P.V.V.; BOOTE, K. J.; ALLEN JR., L. H. SHEELY, J. E.; THOMAS, J. M. G. Species, ecotype and cultivar differences in spikelet fertility and harvest index of rice in response to high temperatures stress. Field Crop Research, 95, p. 398-411, 2006. Disponível em: www.sciencedirect. com Acesso 30 out. 2016.

SANTOS, H. G.; JACOMINE, P. K. T.; ANJOS, L. H. C.; OLIVEIRA, V. A. de; OLIVEIRA, J. B. De; COELHO, M. R.; LUMBRERAS, J. F.; CUNHA, T. J. F. (Ed.) Sistema brasileiro de classificação de solos. 2. ed. Rio de Janeiro: Embrapa Solos, 2006. 306 p.

SIEGEL, S.; CASTELLAN JR, N. J. Estatística Não-paramétrica para Ciências do Comportamento. 2 ed. Porto Alegre, RS: Artmed, 2006. 448 p.
SINGH, A. K.; CHANDRA, N.; BHARTI, R. C.. Effects of genotype and planting time on phenology and performance of rice (Oryza sativa L.). Vegetos, Patna, v. 25, n. 1, p. 151-156, 2012. Disponível em: http:// icarrcer.in/wp-content/uploads/2016/01/EffectOfGenotype.pdf Acesso em 14 jun. 2017.

SLATON, N.; HELMS, S.; WELLS, B. DD50 computerizedrice management program. In: HELMS, R.S. (Ed.). Rice production handbook. Little Rock, AR: University of Arkansas, 1996. p. 24-27. (Miscellany Publication, 192).

SOCIEDADE SUL-BRASILEIRA DE ARROZ IRRIGADO (SOSBAI). Reunião Técnica da Cultura do Arroz Irrigado (25.: 2003: Balneário Camboriú, RS). Arroz irrigado: Recomendações técnicas da pesquisa para o Sul do Brasil. Itajaí, SC:SOSBAI, 2003.126p.

SOCIEDADE SUL-BRASILEIRA DE ARROZ IRRIGADO (SOSBAI). Reunião Técnica da Cultura do Arroz Irrigado (31.: 2016 : Bento Gonçalves, RS). Arroz irrigado: Recomendações técnicas da pesquisa para o Sul do Brasil. Pelotas: SOSBAI, 2016. 200p.

STANSEL, J.W. The rice plant - its development and yield. In: SIX DECADES OF RICE RESEARCH IN TEXAS. Beaumont: Texas Agricultural Experiment Station, 1975. p. 9-21.

STEINMETZ, S.; FAGUNDES, P. R. R.; MAGALHÃES JÚNIOR, A. M. de; SCIVITTARO, W. B.; DEIBLER, A. N.; ULGUIM, A. da R.; NOBRE, F. L. de L.; PINTANEL, J. B. A.; OLIVEIRA, J. G.; SCHNEIDER, A. B. Determinação dos graus-dia e do número de dias para atingir o estádio de diferenciação da panícula de cultivares de arroz irrigado. Pelotas:Embrapa Clima Temperado, 2009a. 29p. (Embrapa Clima Temperado. Boletim de Pesquisa e Desenvolvimento, 88).

STEINMETZ, S.; FAGUNDES, P. R. R.; MAGALHÃES JÚNIOR, A. M. de; SCIVITTARO, W. B.; DEIBLER, A. N.; ULGUIM, A. da R.; NOBRE, F. L. de L.; PINTANEL, J. B. A.; OLIVEIRA, J. G.; SCHNEIDER, A. B. Soma térmica e número de dias para atingir os principais estádios de desenvolvimento de 16 cultivares de arroz irrigado. Pelotas:Embrapa Clima Temperado, 2009b. 31p. (Embrapa Clima Temperado. Boletim de Pesquisa e Desenvolvimento, 89).

STEINMETZ, S.; DEIBLER, A.; N.; SILVA, J. B. da. Estimativa da produtividade de arroz irrigado em função da radiação solar global e da temperatura mínima do ar. Ciência Rural, Santa Maria, v. 43, n. 2, p. 206-211, fev., 2013a.

STEINMETZ, S.; PETRINI, J. A.; ALMEIDA, I. R. de; MAGALHÃES JÚNIOR, A. M. de; FAGUNDES, P. R. R.; DEIBLER, A. N.;RADIN, B.; PRESTES, S. D.; SILVA, M. F. da; BERMUDEZ, D. A. Uso do método de graus-dia para estimar a data de ocorrência dos principais estádios de desenvolvimento de subgrupos de cultivares de arroz irrigado no Rio Grande do Sul. Versão Resumida. Pelotas:Embrapa Clima Temperado, 2013b. 108p. (Embrapa Clima Temperado. Boletim de Pesquisa e Desenvolvimento, 205).

STEINMETZ, S.; CUADRA,S. V.; PEREIRA, C. B.; SANTOS, E. L. dos; ALMEIDA, I. R. de. GD Arroz: programa baseado em graus-dia para estimar a data de diferenciação da panícula visando a adubação nitrogenada cobertura. Pelotas:Embrapa Clima Temperado, 2014. 12p. (Embrapa Clima Temperado. Circular Técnica, 155).

STEINMETZ, S.; CUADRA,S. V.; PEREIRA, C. B.; SANTOS, E. L. dos; ALMEIDA, I. R. GD Arroz: programa baseado em graus-dia como suporte ao planejamento e à tomada de decisão no manejo do arroz irrigado. Pelotas:Embrapa Clima Temperado, 2015. 8p. (Embrapa Clima Temperado. Circular Técnica, 162).

STRECK, N.A.; BOSCO, L. C.; MICHELON, S.; WALTER, L. C.; MARCOLIN, E. Duração do ciclo de desenvolvimento de cultivares de arroz em função da emissão de folhas no colmo principal. Ciência Rural, Santa Maria, v.36, n.4, p.1086-1093, 2006a.

STRECK, N.A.; BOSCO, L. C.; MICHELON, S.; ROSA, H. T.; WALTER, L. C.; PAULA G. M. de; CAMARA, C.; LAGO, I.; MARCOLIN, E. Avaliação da resposta ao fotoperíodo em genótipos de arroz irrigado. Bragantia, Campinas, v.65, n.4, p.533-541, $2006 \mathrm{~b}$. 
WATSON, N.T.; COUNCE, P.A.; SIEBENMORGEN, T.J. Growth stages of 12 rice cultivars (Oryza sativa L.) expressed in DD50 thermal heat units. Disponível em: http//www.arkrice.org/research_results/2004_ PDFs/529_2.pdf Acesso 15 jul. 2006.

WILSON JUNIOR., C. E.; NORMAN, R. J.; SLATON, N. A.; BRANSON, J. W.; BOOTHE, D. L. DD50 computerized rice management program. Little Rock, AR: University of Arkansas: Division of Agriculture: Cooperative Extension Service [2015?]. (Agriculture and Natural Resources.

Computer Technical Series). Disponível em: <https://www. uaex.edu/ publications/PDF/FSA-2124.pdf>. Acesso em: 15 jul. 2015.
WREGE, M. S.; STEINMETZ, S.; REISSER JÚNIOR, C.; ALMEIDA I. R. de (Editores técnicos). Atlas climático da Região Sul do Brasil: Estados do Paraná, Santa Catarina e Rio Grande do Sul. Pelotas: Embrapa Clima Temperado; Colombo: Embrapa Florestas, 2011. 211p.

YOSHIDA, S. Fundamentals of rice crop science. Los Baños: IRRI, 1981 $269 p$.

REFERENCIAÇÃO STEINMETZ, S.; CUADRA, S. V.; ALMEIDA, I. R.; MAGALHÃES JÚNIOR, A. M.; FAGUNDES, P. R. R. Soma térmica e estádios de desenvolvimento da planta de grupos de cultivares de arroz irrigado. Agrometeoros, Passo Fundo, v.25, n.2, p.405-414, 2017. 


\title{
Thermal time and plant development stages of irrigated rice groups of cultivars
}

\author{
Silvio Steinmetz ${ }^{(*)}$, Santiago Vianna Cuadra ${ }^{1}$, Ivan Rodrigues de Almeida ${ }^{1}$, Ariano Martins de Magalhães Júnior ${ }^{1}$ and Paulo \\ Ricardo Reis Fagundes ${ }^{1}$ \\ ${ }^{1}$ Embrapa Clima Temperado, Rodovia BR 392, km 78, Caixa Postal 403, CEP 96.010-971 Pelotas, RS, Brazil. E-mails: silvio.steinmetz@embrapa.br, \\ santiago.cuadra@embrapa.br, ivan.almeida@embrapa.br, ariano.martins@embrapa.br and paulo.fagundes@embrapa.br \\ ${ }^{(*)}$ Corresponding author
}

\section{ARTICLE INFO}

\section{Article history:}

Received 29 June 2017

Accepted 27 December 2017

Index terms:

Oryza sativa L.

degree-days

phenology

crop management

\section{ABSTRACT}

The recommendation from the agricultural research institutions is that the crop management practices should be done according to the plant development stages (PDS). The problem is that the occurrence of these PDS is variable, because it is dependent on temperature. Therefore, it is preferable to estimate them using growing degree-days (GDD), rather than the number of days (ND) in the calendar. The aim of this study was to determine the ND and the GDD necessary to reach six PDS of four groups, involving 34 paddy rice cultivars. Field experiments were carried out at the Embrapa Temperate Climate Center (ETB), located in Capão do Leão, State of Rio Grande do Sul, Brazil, during 12 crop seasons. Ten plants of each cultivar were tagged for growth stage determination during the crop cycle. The GDD was calculated as the sum of the daily values resulting from the difference between the mean air temperature and the minimal base temperature $\left(11^{\circ} \mathrm{C}\right)$ from the emergence until each growth stage. The results indicate that the number of days and the GDD to reach the different plant development stages vary with the cycle's length of the cultivars, being smaller in the Very Short cycle group, intermediate in the Short and Medium cycle groups and larger in the Long cycle group. 